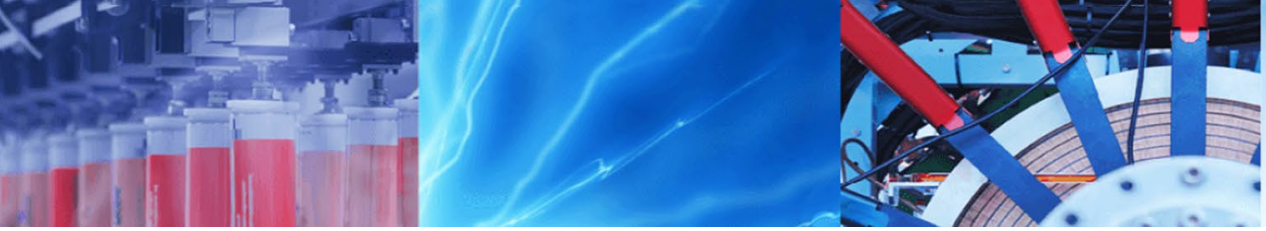

Review Paper

\title{
Mechanical behavior of CFRP on steel surface molded and bonded by vacuum-assisted resin transfer molding technology
}

\author{
Genki Mieda ${ }^{1} \cdot$ Hitoshi Nakamura $^{2} \cdot$ Takahiro Matsui $^{3} \cdot$ Yutaka Ochi $^{4} \cdot$ Yukihiro Matsumoto $^{1}$ (i)
}

(c) Springer Nature Switzerland AG 2019

\begin{abstract}
This research is aimed to develop repair and reinforcement methods with excellent workability and usefulness for steel structural members that have been damaged through aging. Fiber-reinforced plastic, which has been used in various fields in recent years, is also used for building and civil engineering. Especially, it is assumed that carbon fiber-reinforced plastic (CFRP) has light weight and high-strength mechanical properties. Conventional methods of repair and reinforcement using CFRP are mainly hand-lay-up molding methods using carbon fiber sheet and adhesion methods using CFRP plate. However, both methods have some issues. Therefore, we apply the vacuum-assisted resin transfer molding to repair and reinforce steel structural members; the proposal of a construction procedure and a basic investigation of bond strength were carried out. In the basic investigation, a double-strap tensile shear test and a three-point bending test of steel/CFRP composite specimens were carried out. In the double-strap tensile shear test, in order to improve the adhesiveness of CFRP, the adhesive strength against shear force was compared between the specimen pre-coated with resin and a specimen not coated with resin after surface treatment. The results showed that the pre-coated specimen had high strength and stability. In the three-point bending test, bond strength and fracture mode against bending force were analyzed using adhesion length and number of laminated carbon fiber sheets as parameters. From the finite element method, the stress when peeling occurs due to the bending deformation was estimated and compared with the experimental result.
\end{abstract}

Keywords CFRP · Composite structure $\cdot$ VaRTM $\cdot$ Bond strength

\section{Introduction}

In recent years, one of the problems that the construction industry has is the aged deterioration of structures. In particular, the enormous number of structures constructed during the period of high economic growth will soon reach 50 years since construction in Japan [1]. The performance deterioration due to corrosion and thinning with aging are also reported in the field of steel structures. Moreover, research and development related to repair and reinforcement technology of steel structural members are actively pursued in various countries [2,3]. It is desired that suspend the construction of repair and reinforcement should be carried out as short as possible. Hence, rapid repair and reinforcement are required, and a method excellent in handling on the construction site is expected. In the repair and reinforcement of existing structures, it is feared that influence on substructure due to increasing the structural weight and increase in the seismic load will occur through repair and reinforcement. Therefore, it

$\checkmark$ Yukihiro Matsumoto, y-matsum@ace.tut.ac.jp; Genki Mieda, g155503@edu.imc.tut.ac.jp; Hitoshi Nakamura, hnaka@tmu.tut.ac.jp; Takahiro Matsui, Takahiro_Matsui@nts.toray.co.jp; Yutaka Ochi, Yutaka_Ochi@nts.toray.co.jp | 'Department of Architecture and Civil Engineering, Toyohashi University of Technology, 1-1 Hibarigaoka, Tempaku-cho, Toyohashi, Aichi, Japan. ${ }^{2}$ Department of Civil and Environmental Engineering, Tokyo Metropolitan University, 1-1 Minami-Osawa, Hachioji, Tokyo, Japan. ${ }^{3}$ ACM Technical Department, Toray Industries, Inc., 2-1-1 Muromachi Nihonbashi, Chuo-ku, Tokyo, Japan. ${ }^{4}$ Advanced Composite Center, Toray Industries, Inc., 9-1 Oechou Minatoku, Nagoya, Aichi, Japan. 
is assumed that carbon fiber-reinforced polymer (CFRP), having light weight and high-strength mechanical properties, would be a material suitable for repair and reinforcement of structures, and an adhering method using CFRP is noticed $[4,5]$. Conventional methods of repair and reinforcement by CFRP are mainly hand-lay-up molding methods using carbon fiber sheet and adhesion methods using CFRP plate [6]. However, in the former case, the construction time is expanded by multiple laminations and large area molding, and the latter has difficulty in application to a curved surface. So, there is a need for the development of an adhesion method that can be adopted by on-site construction where many restrictions exist. Based on these backgrounds, the vacuum-assisted resin transfer molding (VaRTM) method, which is the manufacturing method used for the blades of wind power generation facilities, was adopted in this study. This molding method has some advantages which are that it is easy to form with multi-layers and in a wide range, can be expected to have high fiber volume content, and shortens construction time by simultaneously forming and bonding $[7,8]$. To apply this method to the repair and reinforcement of steel structures, the basic bond strength was investigated. In the basic investigation, a double-strap tensile shear test and a three-point bending test of some steel/CFRP composite specimens were performed.

\section{Adhesive molding method by VaRTM technology}

VaRTM is a molding method that impregnates with resin using vacuum depressurization. This molding method, therefore, provides excellent workability because it is closed mold method, it is possible to develop a mold that contains a large amount of reinforcement material, which will have excellent reliability and reproducibility. VaRTM is used, for example, in the blades of wind turbines, FRP structural elements in aircraft and in the automobile field [9]. A female mold is a material with high stiffness, and a male mold uses a plastic film so that it can follow the shape of the reinforcement material during vacuum. If necessary, a coat of gel can be applied to the female mold. After this, reinforcement material, peel ply, and flow media are stacked in this order, before being sealed with a film and vacuum depressurization. When a predetermined vacuum pressure (approximately $-100 \mathrm{kPa}$ ) is reached, the resin is dried and forms into the shape of its surroundings, then the curing and film are peeled off, and demolding occurs. Figure 1 shows a diagram of the VaRTM method. In this study, a female mold is used as steel for the experiment to apply to repair and reinforcement of existing steel structural members.

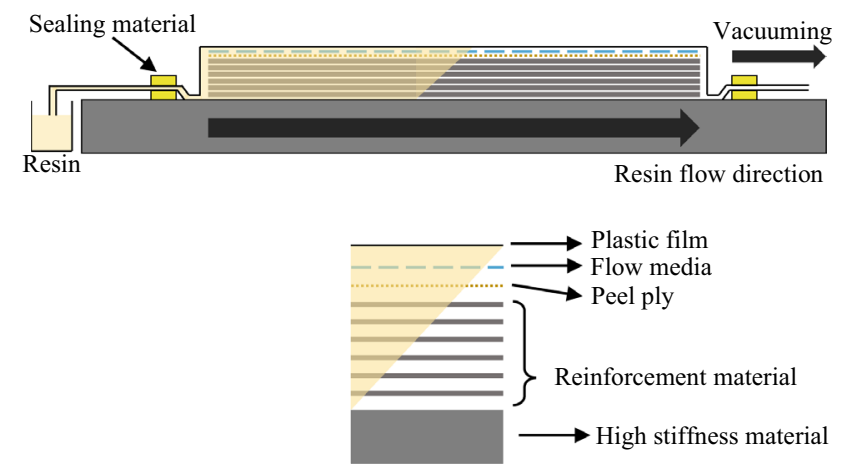

Fig. 1 A schematic sectional view of the VaRTM, showing the laminated structure of necessary materials and reinforcing materials

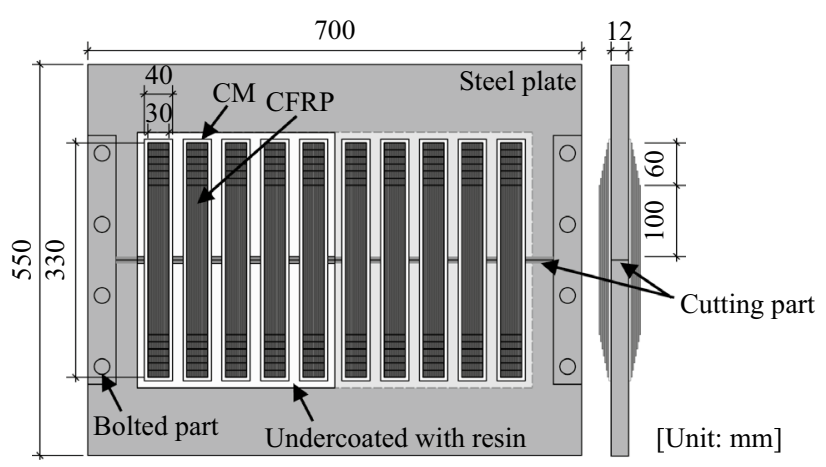

Fig. 2 The molding dimensions of the double-strap tensile shear test specimens based on Fig. 1

\section{Double-strap tensile shear test}

\subsection{Experimental specimens}

Figure 2 shows the dimensions of the molding system. A steel plate was made of SS400 (typical mild steel used in Japan) with a thickness of $12 \mathrm{~mm}$, and molding was carried out on each side by VaRTM technology. In order to make it a double-strap type, the steel plate was bolted at both ends after cutting. The experimental parameters were with or without a resin "undercoat". The term "undercoat" means to coat in advance the impregnation epoxy resin (Toray ACE, AUP40) to the bonding surface before lamination to improve workability, secure the adhesive layer, and to prevent corrosion after surface treatment. The adhesive strength in the bonding method depends on the thickness and condition of the adhesive layer, and it seems to stabilize by securing a suitable adhesive layer and improving adhesiveness. As a result, with/without undercoat was adopted as an experimental parameter. (Hereinafter, the undercoat specimen is "W specimen", and without undercoat specimen 
is "D specimen".) The used reinforcement materials are a medium elastic unidirectional carbon fiber sheet (CF sheet) which has a thickness of $0.217 \mathrm{~mm}$, an elastic modulus of $440 \mathrm{GPa}$ and $400 \mathrm{gsm}$ of weight (Toray, UM4640 ) as well as a chopped strand grass mat (CM) which is set up between the steel surface and the CF sheet and is $450 \mathrm{gsm}$ of weight. The CF sheet was $30 \mathrm{~mm}$ width, and the number of laminations is 7 layers on each side, totaling 14 layers so that the ratio of axial stiffness of steel material and CFRP is about 1:2. A tapered lamination of $10 \mathrm{~mm} /$ layer was adopted to relieve stress concentration at the end of CFRP [10]. Also, to avoid the yielding of the steel plate before the CFRP breaking occurred, a tensile shear test was carried out after cutting the steel plate width about $50 \mathrm{~mm}$ after molding. The name of the experimental specimen is "with or without resin undercoat (W or D)—specimen number".

\subsection{The procedure of molding and bonding by VaRTM technology}

Figure 3 shows the procedure of VaRTM. First, the steel surface was treated by a rotary blaster [11]. Thereafter, the roughness was measured by surface roughness tester (Mitutoyo, SJ-210) to confirm that the ten-point average roughness was over $20 \mu \mathrm{m}$. Then, in order to prevent air leakage from the cut part at the time of VaRTM molding, an epoxy-based mending material (Konishi, BQM100) was used to seal $\pm 5 \mathrm{~mm}$ at the cut part. Thereafter, as shown in Fig. 3a, the undercoat was performed and surrounded by "sealing material" for affixing a plastic film around the molding area. Figure $3 \mathrm{~b}$ is the state of the $\mathrm{CM}$ and the $\mathrm{CF}$ sheet laminated onto the treated surface. Figure $3 \mathrm{c}$ shows the state for the "peel ply" which is to separate other than CFRP at the time of demolding and "flow media" to flow resin. As shown in Fig. 3f, by placing a vacuum section on the upper side and resin transferring section on the lower side, it is possible to vacuum while sufficiently impregnating the resin. Figure $3 \mathrm{~g}$, $\mathrm{h}$ shows the state after impregnation and demolding.

\subsection{The fiber volume content of specimens}

As shown in Table 1, the fiber volume content $V_{f}$ was calculated using Eq. (1) [12]. These thicknesses are measured by a coating thickness meter (Sanko, SWT-9000 and Fe-10). The $t_{\mathrm{CFRP}+\mathrm{CM}}$ is evaluated by its averaging six points on both sides, and $t_{\mathrm{CM}}$ is measured after demolding; it was $0.62 \mathrm{~mm}$. And the $t_{C F \text { sheet }}$ used a nominal thickness of the used CF sheet of $0.217 \mathrm{~mm} /$ layer. Table 1 shows that the average of the fiber volume content exceeded $50 \%$ throughout all specimens. In the with/without undercoat, since the change in the fiber volume content is hardly observed and the coefficient of variation is also stable, it is considered that there is no influence on the CFRP thickness.

$V_{\mathrm{f}}=\frac{N_{\text {ply }} \cdot t_{\mathrm{CF} \text { sheet }}}{t_{\mathrm{CFRP}+\mathrm{CM}}-t_{\mathrm{CM}}}$

$t_{C F R P+C M}$ total thickness, $t_{C M}$ CM thickness, $N_{\text {ply }}$ number of laminations, $t_{C F \text { sheet }}$ total CF sheet thickness.

\subsection{Result and discussion}

Figure 4 shows setup for the double-strap tensile shear test and dimensions of the experimental specimen, strain gauge (SG) positions, and classification of bonded surfaces. A to $D$ in Fig. 4 are used to indicate a fractured surface after the experiment described below.

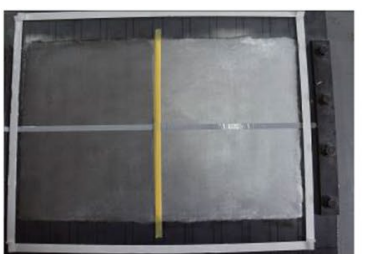

(a)Undercoat (left side)

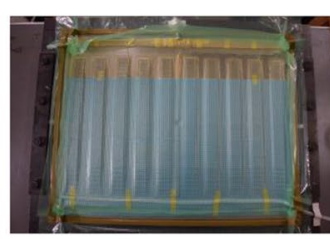

(e) After vacuuming $(-100 \mathrm{kPa})$

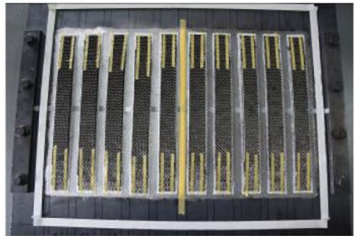

(b) Set up reinforcing materials

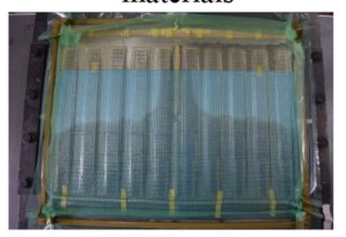

(f) A state of resin impregnation

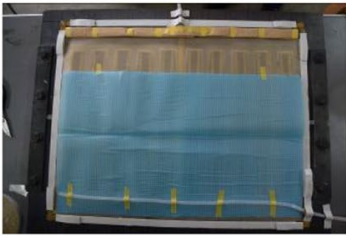

(c)Set up peel ply and flow media

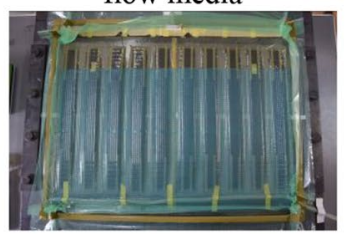

(g) Curing

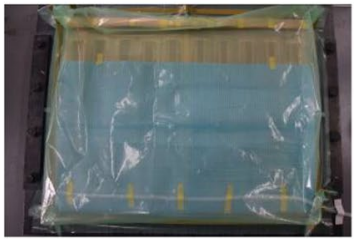

(d)Set up plastic film

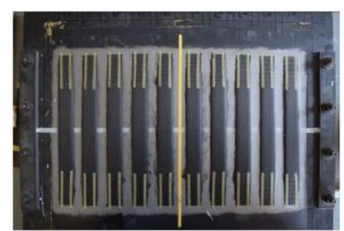

(h) After demolded

Fig. 3 The procedure for actually molding specimens 
Table 1 The measurement results of the CFRP thickness of the specimens after molding and the fiber volume content obtained by its result are shown
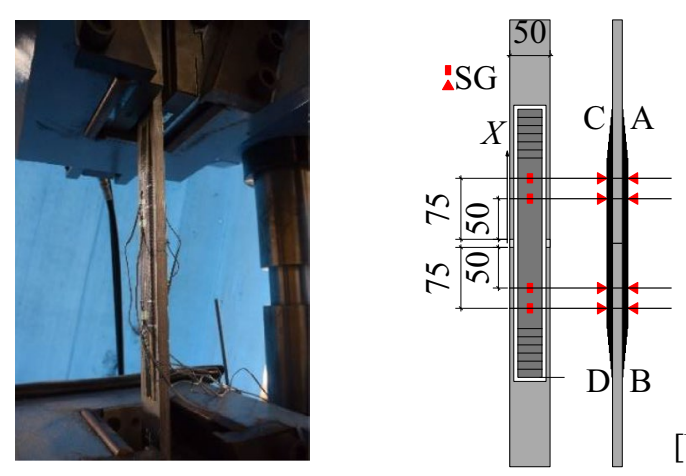

\begin{tabular}{lllllll}
\hline Specimens & $t_{\text {CFRP }+ \text { CM }}(\mathrm{mm})$ & \multicolumn{1}{l}{$V_{\mathrm{f}}$} & & & \\
\cline { 3 - 6 } & & $(\%)$ & Average (\%) & $\begin{array}{l}\text { Coefficient } \\
\text { of variation }\end{array}$ & Average (\%) & Coefficient of variation \\
\hline W-1 & 3.655 & 50.05 & 50.01 & 0.00476 & 50.22 & 0.00874 \\
W-2 & 3.661 & 49.95 & & & \\
W-3 & 3.660 & 49.97 & & & \\
W-4 & 3.634 & 50.40 & & & \\
W-5 & 3.679 & 49.66 & & & \\
D-1 & 3.664 & 49.91 & 50.04 & 0.00963 & & \\
D-2 & 3.583 & 51.27 & & & \\
D-3 & 3.658 & 50.01 & & & \\
D-4 & 3.625 & 50.55 & & & \\
D-5 & 3.631 & 50.44 & & & \\
\hline
\end{tabular}

Fig. 4 The condition of the experiment and dimensions of the specimen, and also indicate the attaching posit ions of the strain gauges

\subsubsection{Bond strength against a shear force}

Figure 5 shows $\sigma_{\text {shear }}$-displacement relationship, and Table 2 shows the maximum loading, fracture surface and bond strength against a shear force of each specimen. The $\sigma_{\text {shear }}$ means the bond stress against shear force and calculated by Eq. (2); the displacement is corresponding to the crosshead displacement of testing machine. As a result of the double-strap tensile shear test, there was no significant difference in the bond strength against a shear force between the W specimen and the D specimen; however, the $W$ specimen had a low coefficient of variation as compared with the $D$ specimen. Although there is almost no difference in CFRP thickness, it seems that the improvement in the adhesion at the interface leads to this result. Figure 6 shows the fracture surface (bonded surface) after the experiment. In both $\mathrm{W}$ and $\mathrm{D}$ specimens, the fracture mode results in a debonding between the steel material and the CM interface in the center part, or delamination of the CFRP (material destruction) in the other areas [13]. This result seems to correspond to bond strength against a shear force and is not varied between $\mathrm{W}$ specimen and $\mathrm{D}$ specimen because the fracture mode does not change.

$\sigma_{\text {shear }}=\frac{P}{A_{\text {bond }}}$

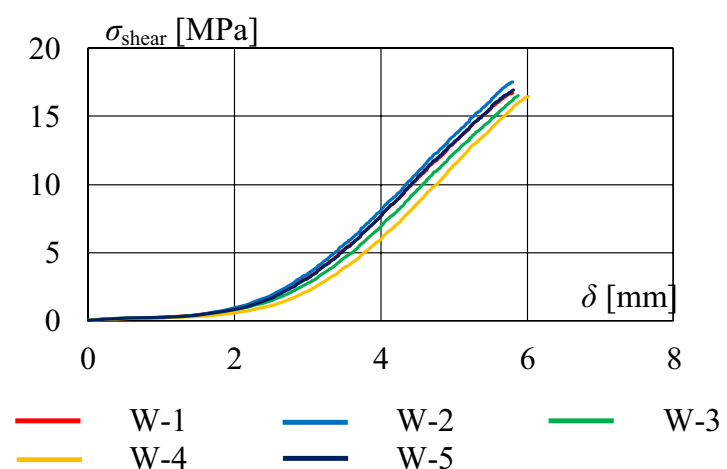

(a) W-specimens

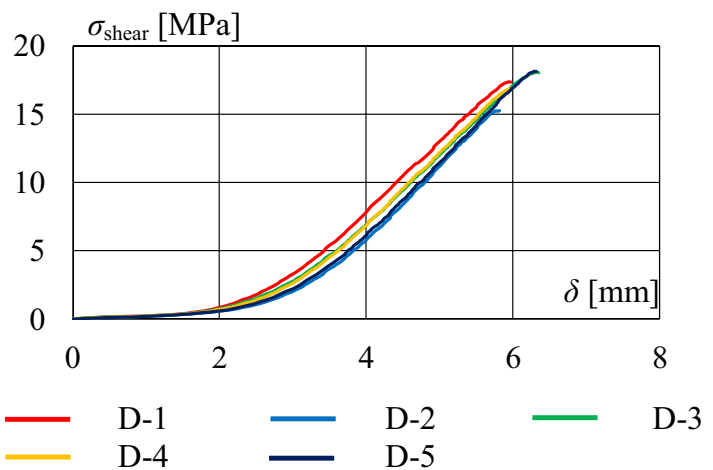

(b) D-specimens

Fig. 5 A bond stress against the shear force-displacement relationship obtained by the double-strap tensile shear test 
Table 2 The results of double-strap tensile shear test

\begin{tabular}{|c|c|c|c|c|c|c|c|}
\hline \multirow[t]{2}{*}{ Specimens } & \multirow{2}{*}{$\begin{array}{l}\text { Maximum } \\
\text { loading }(k N)\end{array}$} & \multirow{2}{*}{$\begin{array}{l}\text { Fracture } \\
\text { surface }\end{array}$} & \multicolumn{5}{|c|}{ Bond strength against a shear force } \\
\hline & & & (MPa) & Average (MPa) & $\begin{array}{l}\text { Coefficient of } \\
\text { variation }\end{array}$ & Average (MPa) & Coefficient of variation \\
\hline$W-1$ & 160.320 & $\mathrm{~B}, \mathrm{C}$ & 16.70 & 16.83 & 0.02291 & 16.98 & 0.0469 \\
\hline$W-2$ & 168.304 & $B, D$ & 17.53 & & & & \\
\hline W-3 & 158.868 & $\mathrm{~B}, \mathrm{C}$ & 16.55 & & & & \\
\hline W-4 & 157.896 & A, D & 16.45 & & & & \\
\hline W-5 & 162.480 & $\mathrm{~B}, \mathrm{C}$ & 16.93 & & & & \\
\hline D-1 & 166.756 & $\mathrm{~B}, \mathrm{C}$ & 17.37 & 17.14 & 0.06051 & & \\
\hline D-2 & 146.640 & $\mathrm{~B}, \mathrm{C}$ & 15.26 & & & & \\
\hline D-3 & 173.300 & $\mathrm{~B}, \mathrm{C}$ & 18.05 & & & & \\
\hline $\mathrm{D}-4$ & 162.052 & $\mathrm{~B}, \mathrm{C}$ & 16.88 & & & & \\
\hline D-5 & 173.880 & $A, D$ & 18.11 & & & & \\
\hline
\end{tabular}

In the table, the maximum loading, fracture surface, the bond strength against the shear force calculated by the maximum loading and its stability are shown

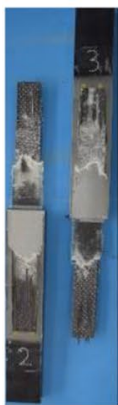

(a) $\mathrm{W}-1$

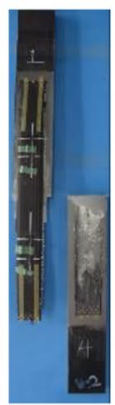

(b) W-2

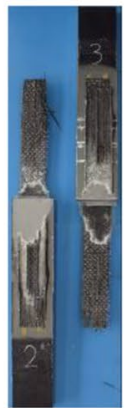

(c) W-3

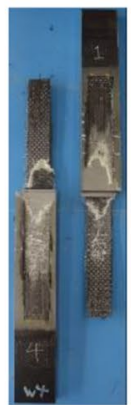

(d) W-4

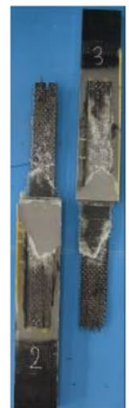

(e) W-5

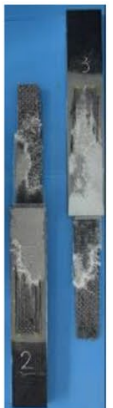

(f) $\mathrm{D}-1$

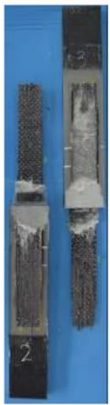

(g) D-2

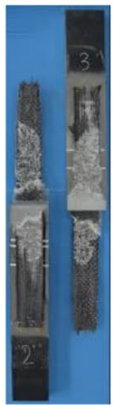

(h) D-3

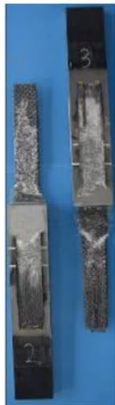

(i) D-4

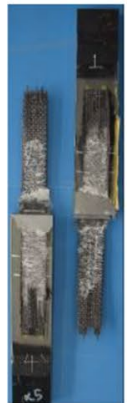

(j) D-

Fig. 6 The fracture surface after the experiment

$P$ the tensile loading, $A_{\text {bond }}$ sum of two bonded areas.

\subsubsection{Bond stress against the shear force: strain relations}

Figure 7 shows the $\sigma_{\text {shear }}$-strain relationship for each surface. Also, on the assumption that the strains of the steel and the CFRP are equal at the position of $X=50 \mathrm{~mm}$ to $75 \mathrm{~mm}$ where the SG is attached, the elastic theory calculated by Eq. (3) is drawn in Fig. 7. In addition, the results by finite element analysis (FEA) are also drawn in Fig. 7. The FEA used an analysis model is shown in Fig. 8. The mechanical properties of the materials are shown in Table 3. The FEA used in the analysis of this study was a two-dimensional model as shown in Fig. 8, and the element was a quadratic rectangle element assuming a plane stress condition. The steel material and the CM are two isotropic elastic materials, and the CFRP is an orthotropic elastic material. The fiber axial direction elastic modulus, the fiber vertical direction elastic modulus and the shear modulus of the CFRP were calculated by the rule of mixture. However, the theoretical equation and FEA are based on the average $t_{\mathrm{CF}}$ of each of the $\mathrm{W}$ and $D$ specimens obtained from Table 1 , and the elastic modulus of CFRP was calculated from this thickness by the rule of mixture [12]. From Fig. 7, at the $X=50 \mathrm{~mm}$ position, the correspondence between the experimental result and Eq. (3) was not confirmed; however, the correspondence with the FEA was shown. From this result, it was confirmed that the strain of steel and CFRP was not equalized at $X=50 \mathrm{~mm}$, whereas, at the $X=75 \mathrm{~mm}$ position, it is considered that the approximately correspondence with Eq. (3), FEA and the experimental results. And, the position to be equal where the strains of the steel and CFRP are equalized is near the position of $X=75 \mathrm{~mm}$. Also, as the maximum loading approaches, the strain of CFRP increases. Since destruction is considered to proceed from the steel material cutting part (center part of the specimen), linearity cannot be maintained in the $\sigma_{\text {shear }}-s$ train relation of $X=50 \mathrm{~mm}$, and similar behavior also occurred at $X=75 \mathrm{~mm}$ which thereafter occurred. In 


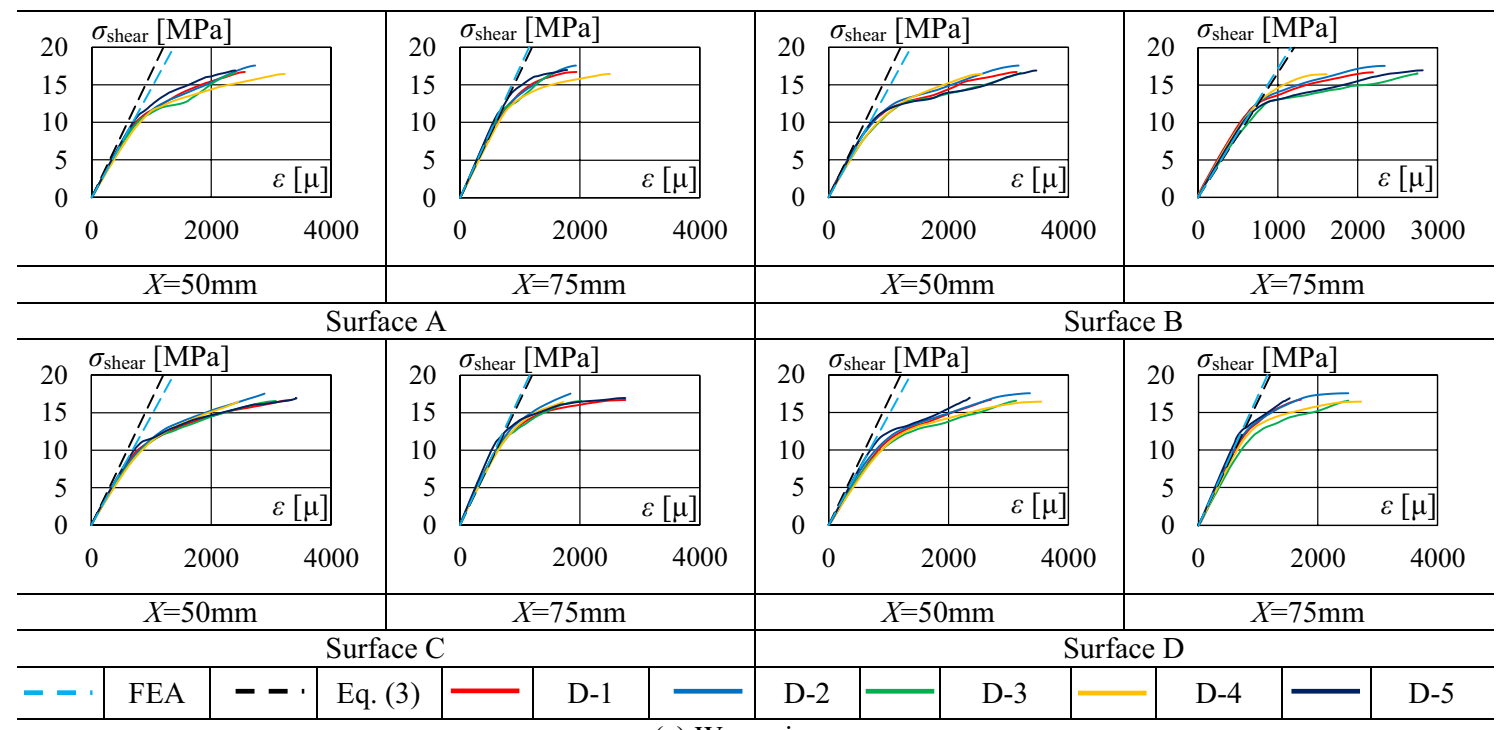

(a) W-specimens

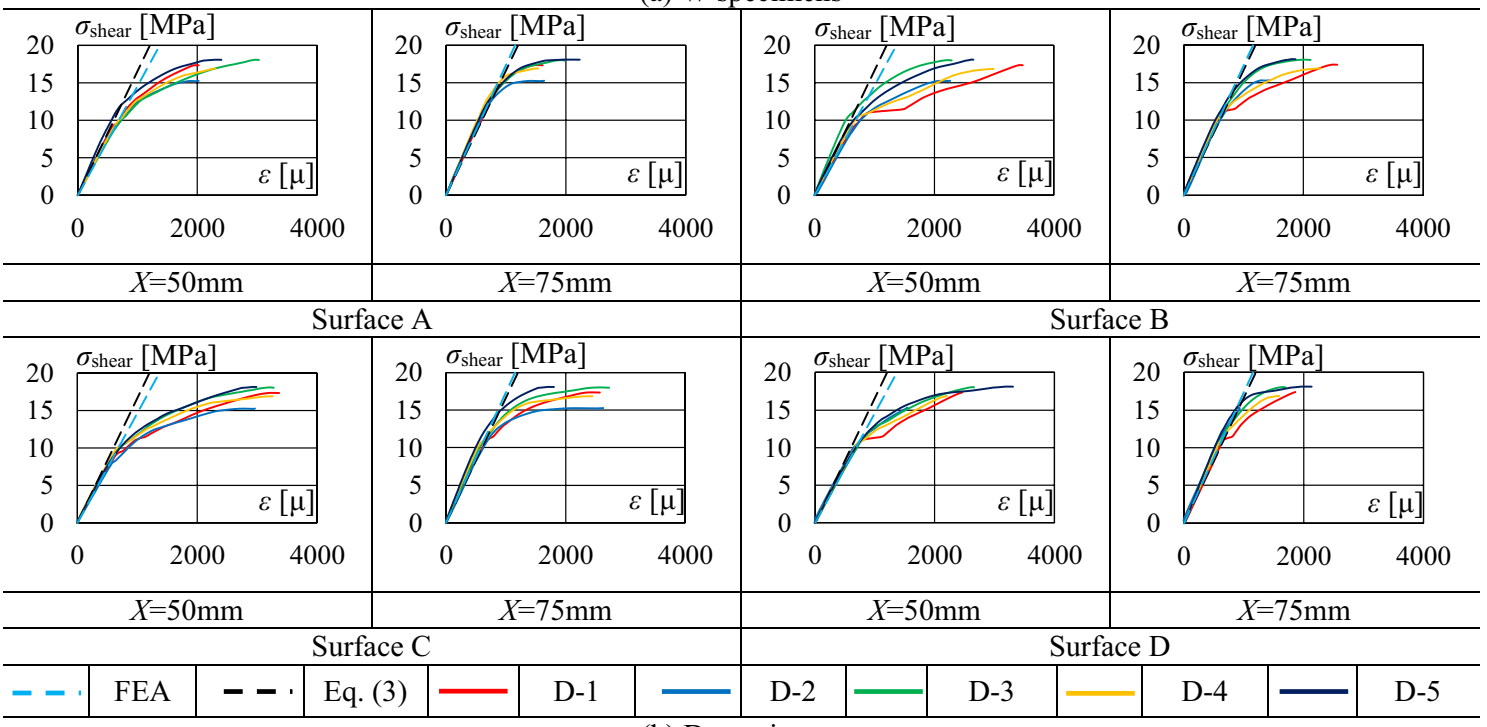

(b) D-specimens

Fig. 7 The bond stress against the shear force-strain relation for each bonding surface of the specimen. In each graph, the theoretical value obtained by Eq. (3) is shown

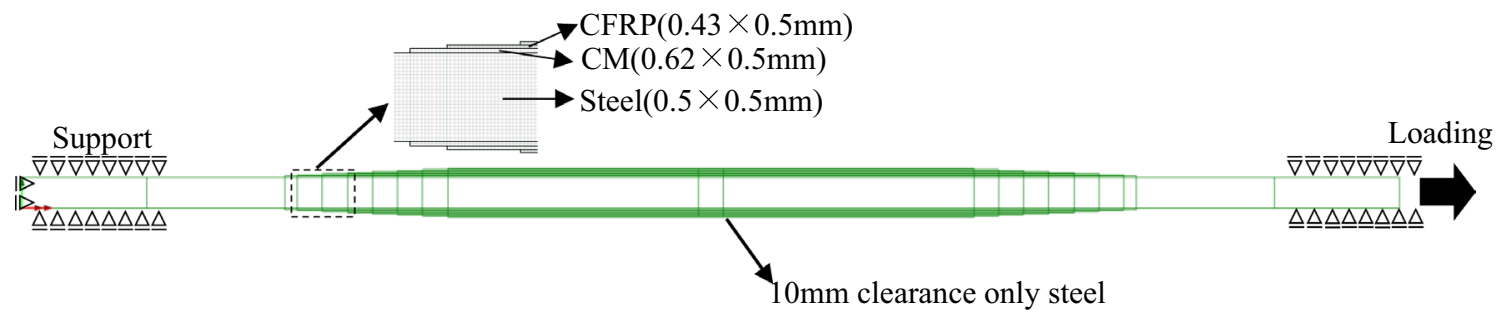

Fig. 8 The FEA model of double-strap tensile shear test

the W specimen, the $\sigma_{\text {shear }}$ at which nonlinearity appears is about $10 \mathrm{MPa}$, and the bond stress against the shear force-strain relationship thereafter shows similar behavior. On the other hand, in the $D$ specimen, there were a precipitous strain increase and variation in behavior, as shown on the bonding surfaces $A, X=75 \mathrm{~mm}$ of 
Table 3 The mechanical properties of materials used in FEA

\begin{tabular}{|c|c|c|}
\hline & Elastic modulus (GPa) & Poisson ratio \\
\hline (a) Steel plate & 200 & 0.3 \\
\hline \multirow[t]{2}{*}{ (b) $\mathrm{CM}$} & 8 & 0.3 \\
\hline & Elastic modulus (GPa) & Shear modulus (GPa) \\
\hline \multicolumn{3}{|c|}{ (c) Epoxy resin and CF sheet } \\
\hline Epoxy resin & 3.9 & 1.5 \\
\hline CF sheet & 440 & 20 \\
\hline
\end{tabular}

the $D-2$ specimen and the bonding surfaces $B$ and $D$ of the D-1 specimen.

$\varepsilon=\frac{P}{b_{\mathrm{s}} t_{\mathrm{s}} E_{\mathrm{s}}+2 b_{\mathrm{cf}} t_{\mathrm{cf}} E_{\mathrm{cf}}}$

$\varepsilon$ strain, $P$ tensile loading, $b_{s}$ steel breadth, $t_{s}$ steel thickness, $E_{s}$ elastic modulus of steel, $b_{c f}$ CFRP breadth, $t_{c f}$ CFRP thickness, $E_{c f}$ elastic modulus of CFRP

\section{Three-point bending test}

\subsection{Experimental specimens}

In this experiment, the same materials as the doublestrap tensile shear test were used; a CFRP was bonded and molded on the tensile side of the steel plate by VaRTM technology. As shown in Table 4, the experimental parameters were the number of laminated CF sheets and its bonding length. The name of the experimental specimen is " $L$ bonding length-the number of laminated CF sheets-specimen number". Figure 9 shows the dimensions of the molding system in the $L 400$ specimens. From the results of the double-strap tensile shear test, all the bonding surfaces of these specimens were undercoated, and a tapered lamination of $10 \mathrm{~mm} /$ layer was also adopted at the end of CFRP. After molding, the experimental specimen is cut at a width of about $40 \mathrm{~mm}$ and a three-point bending test is carried out.

\subsection{The procedure of molding and bonding by VaRTM technology}

Figure 10 shows the procedure of VaRTM for this experiment. As also shown in Sect. 4.1, the molding of the specimens in this experiment was made as two sets of $L 400$ specimens and L220, L320 specimens, to avoid variation for each specimen as much as possible. Unlike the double-strap tensile shear test specimen, the steel is not sealed with epoxy-based mending material because it is not cut at the center.

\subsection{The fiber volume content of specimens}

For the bending specimen, the $V_{f}$ was calculated using Eq. (1) in the same method as the double-strap tensile shear specimen, and it is shown in Table 5. The CM thickness was $0.56 \mathrm{~mm}$ on average. Although the $V_{\mathrm{f}}$ decreased slightly compared to the double-strap tensile shear test experiment, the stability in molding in two lots could be confirmed.

\subsection{Result and discussion}

Figure 11 shows the setup for the three-point bending test, and dimensions of the experimental specimen, SG and displacement meter (DM) positions are shown in Fig. 12. Figure 13 shows some of the fracture modes. In the fracture mode, debonding occurred at the adhesive layer interface at the end of the CFRP in the L220 and L320 specimens. Also, in the $L 400$ specimen, debonding did not occur, but there was a breaking of the CFRP at the center. Figure 14 shows the load-displacement relationships. The displacement shown in Fig. 14 is the average value of the two DMs in Fig. 12. For the convenience of the experimental equipment, measurement results up to maximum deformation of $25 \mathrm{~mm}$ are shown. In addition, the calculated value $P_{\mathrm{y}}$ of the bending yield load in without strengthening steel plate (yielding point $\sigma_{\mathrm{y}}=296 \mathrm{MPa}$ obtained by inspection certificate) and the theoretical formula calculated as the composite cross section by the elastic curve equation are drawn. The theoretical equation calculates the elastic modulus of CFRP by the rule of mixture using the average CFRP thickness obtained from Table 5. Then, considering the taper lamination as shown in Fig. 12, the moment of inertia is calculated and drawn. As can be seen from Fig. 15, the maximum strength and the maximum deformation of each parameter were almost stable, and correspondence
Table 4 The experimental parameters in the threepoint bending test, and the parameters are the number of CFRP laminations and the its bonding length

\begin{tabular}{llllrrr}
\hline & \multicolumn{3}{l}{ Bonding length $(\mathrm{mm})$} \\
\cline { 2 - 7 } & 220 & 11 & 7 & 11 & 7 & 11 \\
\hline Number of laminations & 7 & 2 & 2 & 2 & 4 & 4 \\
\hline
\end{tabular}


Fig. 9 The molding dimensions in the three-point bending test similarly to Fig. 2

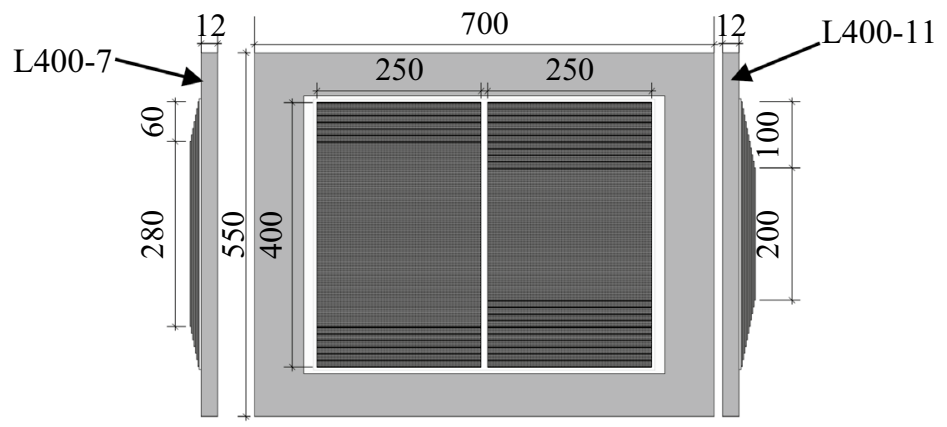

(a)L400 specimens

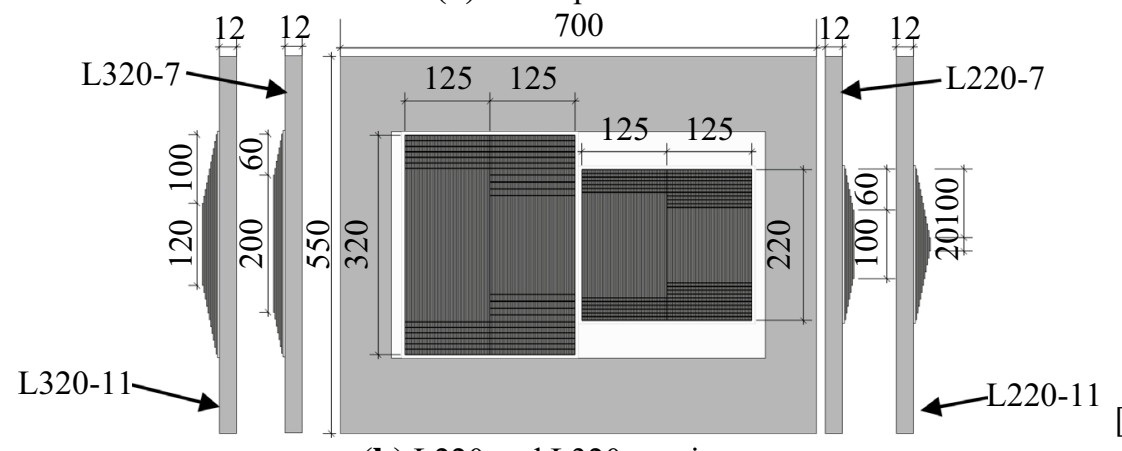

[Unit: mm]

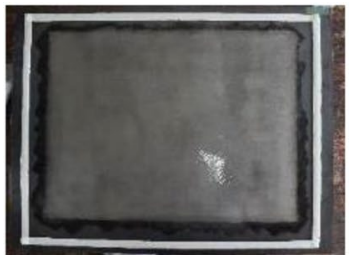

(a) Treated surface and undercoated using by resin

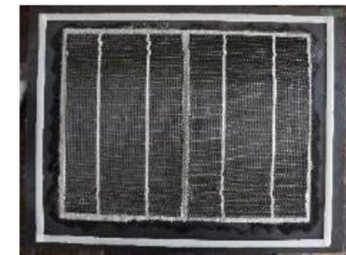

(b) Set up reinforcing materials

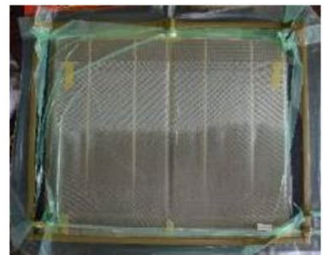

(c) A state of resin impregnation

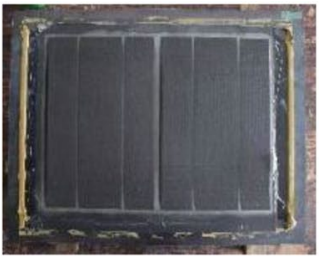

(d) After demolded

Fig. 10 The procedure for actually molding specimens similarly to Fig. 3

with the theoretical equation based on the elastic curve equation was also obtained. As the number of laminated CFRPs increased, the maximum deformation was equivalent in the L220 specimens, but the L320 specimens greatly decreased. Figure 15 shows the load-strain relationships. The strain is the value of SG3 on the tensile side, and the average of SG1 and SG2 on the compression side. As shown in Fig. 13c, the fracture mode is breaking of CFRP at the center, and its strain could be confirmed in the range of about $8000 \mu$ to $9000 \mu$ in the $L 400$ specimens from Fig. $15 a$. Also, in Fig. 15b, c, it was found that debonding occurred in the L220 specimens within the elastic range of the steel plate and debonding occurred in the L320 specimens after the steel plate yielded. From these results, it was confirmed that in the case of reinforcement with the bonding length and the number of laminations like that of the $L 400$ specimens, debonding of the CFRP did not occur after the yield of steel plate and followed the deformation of the steel plate. To elucidate the behavior under bending deformation, there is a need to analyze and estimate the maximum stress in the vertical direction of the bonding surface (peel stress). In repair/reinforcement design, it is considered that debonding under bending deformation can be suppressed by designing the shape and number of laminated parts so as not to exceed the estimated peel stress. However, since it is difficult to measure the peel stress [14], the peel stress of each experimental specimen was estimated using FEA. Then, bond strength and fracture modes were analyzed by FEA results. The FEA used in the analysis of these specimens was a two-dimensional model based on the measured values of each specimen as shown in Fig. 16, and the element was a quadratic rectangle element assuming a plane stress condition. The mechanical properties shown in Table 3 were used for the analysis. In addition, since Fig. 16 is a symmetrical

\section{SN Applied Sciences}


Table 5 The measurement results of the CFRP thickness of the specimens after molding and the fiber volume content obtained by its result are shown similarly Table 1

\begin{tabular}{|c|c|c|c|c|c|c|c|}
\hline \multirow[t]{2}{*}{ Specimens } & \multirow[t]{2}{*}{ Width (mm) } & \multirow[t]{2}{*}{$t_{\mathrm{CFRP}+\mathrm{CM}}(\mathrm{mm})$} & \multicolumn{5}{|l|}{$V_{\mathrm{f}}$} \\
\hline & & & (\%) & Average (\%) & $\begin{array}{l}\text { Coefficient of } \\
\text { variation }\end{array}$ & Average (\%) & Coefficient of variation \\
\hline L400-7-1 & 44.16 & 4.12 & 42.67 & 42.19 & 0.0199 & 44.27 & 0.0349 \\
\hline L400-7-2 & 42.34 & 4.20 & 41.73 & & & & \\
\hline L400-7-3 & 42.91 & 4.16 & 42.19 & & & & \\
\hline L400-7-4 & 43.35 & 4.16 & 42.19 & & & & \\
\hline L400-11-1 & 43.34 & 5.73 & 46.17 & 44.23 & & & \\
\hline L400-11-2 & 42.76 & 5.99 & 43.96 & & & & \\
\hline L400-11-3 & 44.12 & 6.07 & 43.42 & & & & \\
\hline L400-11-4 & 43.43 & 6.06 & 43.40 & & & & \\
\hline L320-7-1 & 39.78 & 3.84 & 46.31 & 46.31 & 0.0305 & & \\
\hline L320-7-2 & 37.38 & 3.84 & 46.31 & & & & \\
\hline L320-11-1 & 38.07 & 5.91 & 44.62 & 44.37 & & & \\
\hline L302-11-2 & 38.77 & 5.97 & 44.12 & & & & \\
\hline L220-7-1 & 41.59 & 3.98 & 44.41 & 45.50 & & & \\
\hline L220-7-2 & 39.43 & 3.82 & 46.59 & & & & \\
\hline L220-11-1 & 38.96 & 5.88 & 44.87 & 45.08 & & & \\
\hline L220-11-2 & 38.20 & 5.83 & 45.29 & & & & \\
\hline
\end{tabular}

Fig. 11 A condition in the experimental specimen with the bonding length of $220 \mathrm{~mm}$ and the number of CFRP laminations of 11 layers

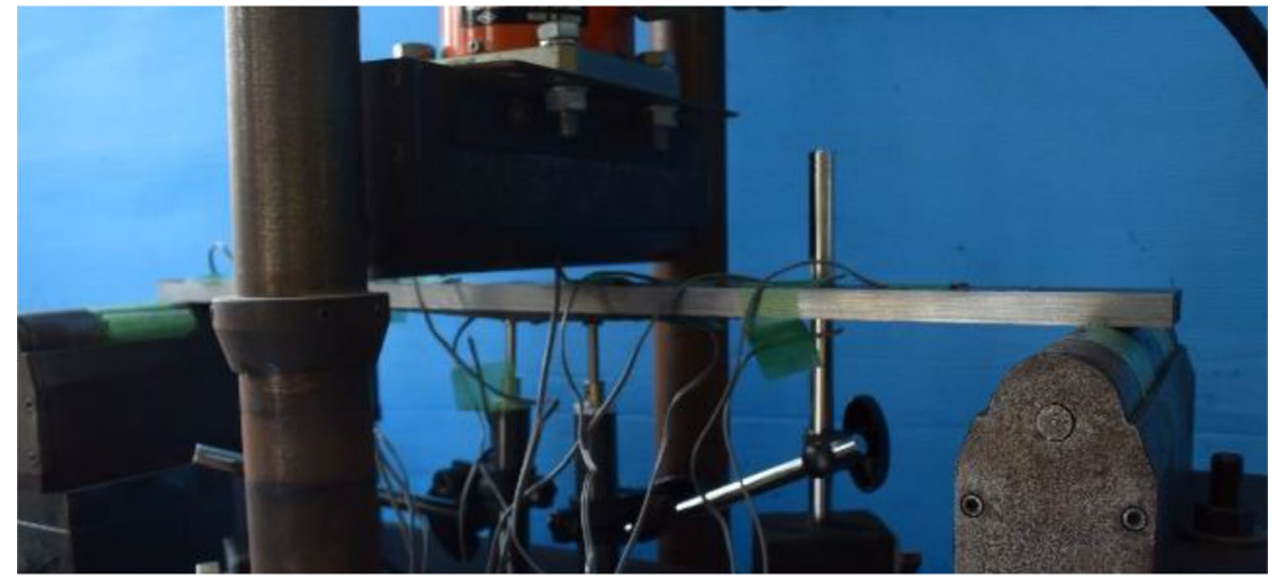

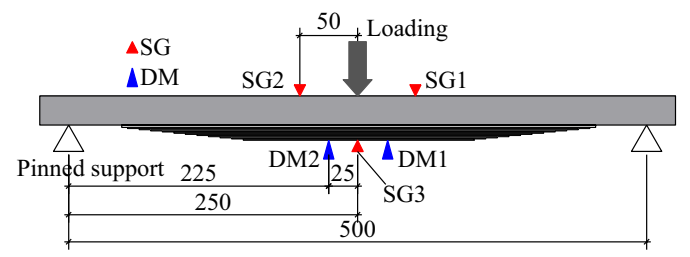

[Unit: $\mathrm{mm}]$

Fig. 12 The bending span, the positions of strain gauge and displacement meter

model, the left part from the center is omitted. The steel material is an isotropic elastoplastic material of a perfectly bilinear model with a yield point of $296 \mathrm{MPa}$. The CM is an isotropic elastic material, and the CFRP is an orthotropic elastic material. The fiber axial direction elastic modulus, the fiber vertical direction elastic modulus and the shear modulus of the CFRP were calculated from the measured thicknesses of the specimens by the rule of mixture used in the same method as the theoretical value of Fig. 14. The estimated position of the peel stress was defined as the boundary of the tapered position between the first layer and the second layer of CFRP. This is the position where the fracture mode through the experiment was also caused by debonding at the interface between the $\mathrm{CM}$ and the steel plate and by the delamination of the CFRP between the first and second layers. In the analysis, one experimental specimen was used for each parameter because the experimental result was stable as shown in Fig. 13. Firstly, the bending 


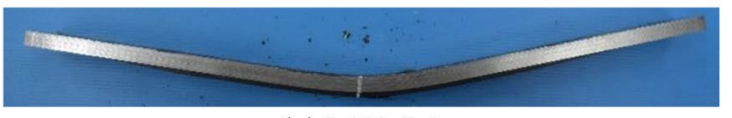

(a) L400-7-1

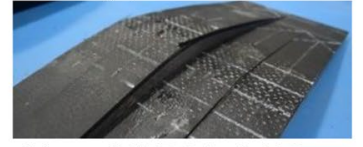

(c) Breaking of CFRP in L400 specimens

(e) L320-11-1

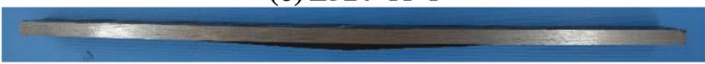

(g) L220-11-1

Fig. 13 The condition of deformation after the experiment

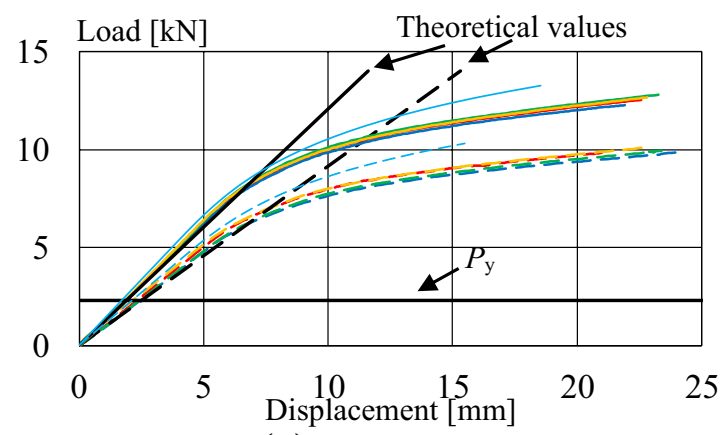

(a) L400 specimens

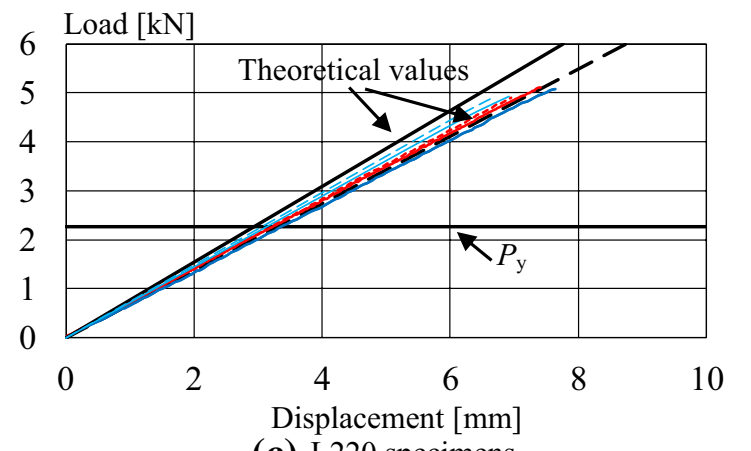

(c) L220 specimens

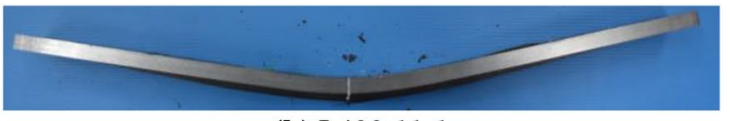

(b) L400-11-1

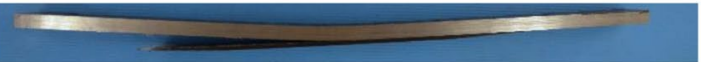

(d) L320-7-1

(f) $\mathrm{L} 220-7-1$

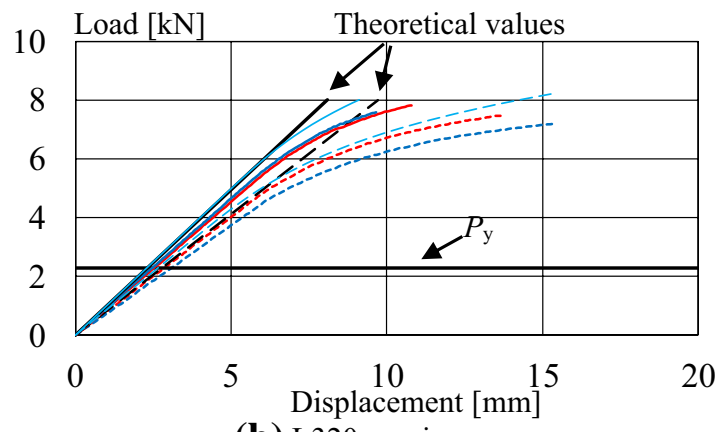

(b) L320 specimens

Dashed line: 7 layers specimens Solid line: 11 layers specimens

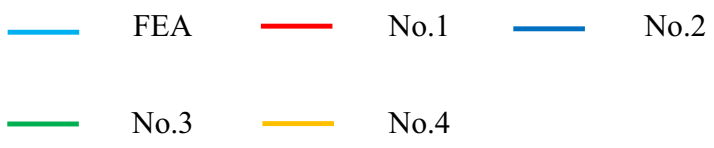

Fig. 14 The load-displacement relation obtained from the experiment. Also, in the figure, the theoretical values by the elastic curve equation are shown

behavior of each specimen was analyzed. From Fig. 17, it can be seen that the peel stress per unit deformation decreases as the bonding length increases. Focusing on the variation in the number of laminated CFRPs for each bonding length, there were hardly any differences in the L220 specimens; however, the peel stress per unit deformation increases as the number of laminated pieces was increased in the L320 specimens. The reason for this result in the $L 220$ specimens is that the bending stiffnesses are generally the same in the 7-layer specimen and the 11-layer specimen. In the case of L220-11, as shown in Fig. 9b, it is expected that CFRP length of the shortest layer is $20 \mathrm{~mm}$, and load-bearing was hardly performed. Also, in Fig. 14c the bending stiffness of L220-7 and L220-11 was generally the same, and the compressive strain of the steel plate in Fig. 15c is also comparable. However, the maximum tensile strain of CFRP was decreased. 
Fig. 15 The load-strain relation obtained from the experiment

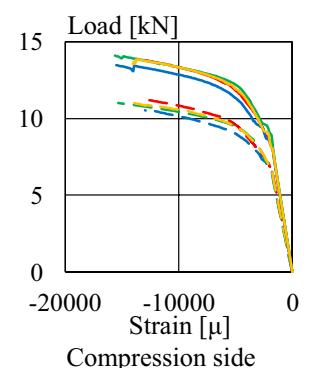

(a) L400 specimens

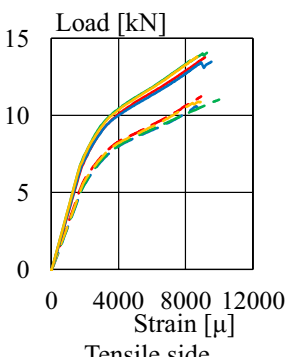

Tensile side
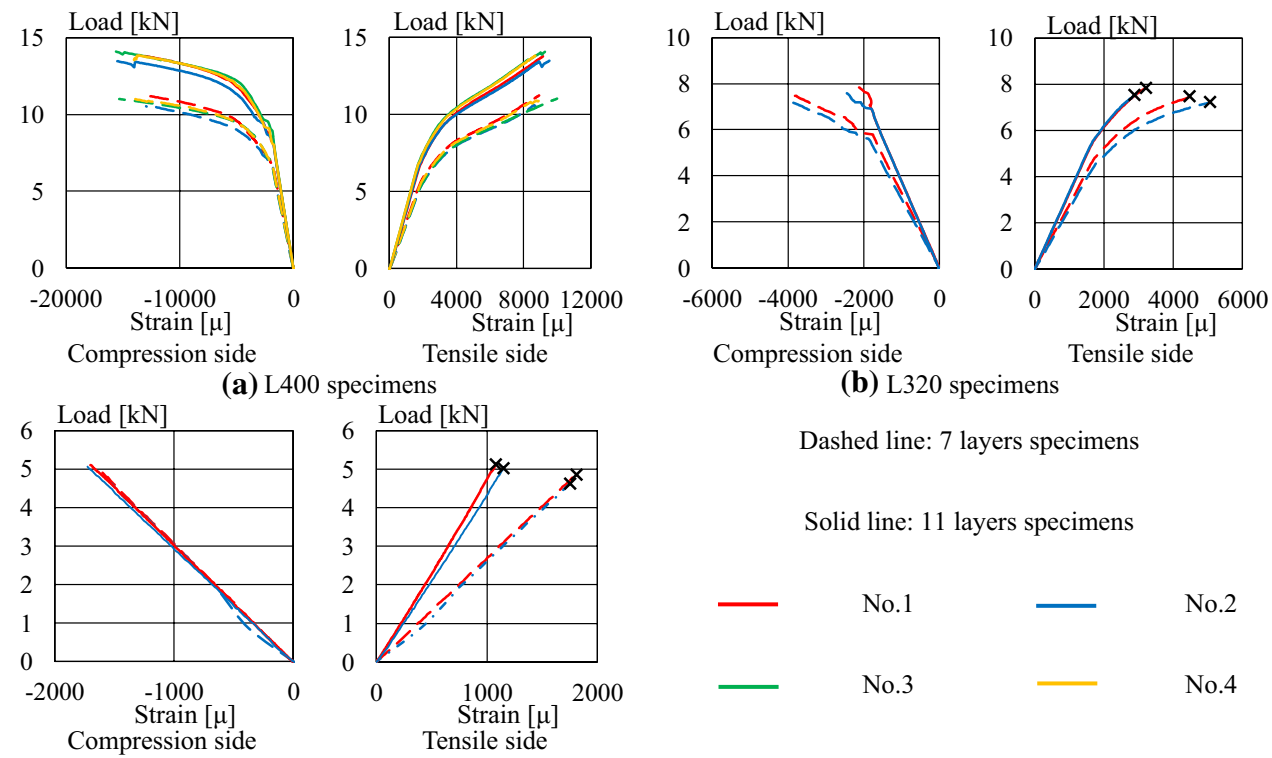

(b) L320 specimens

Dashed line: 7 layers specimens

Solid line: 11 layers specimens

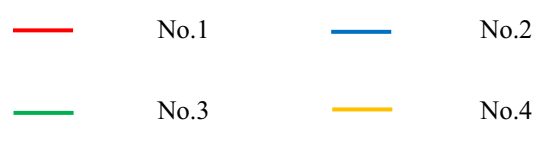

(c) L220 specimens

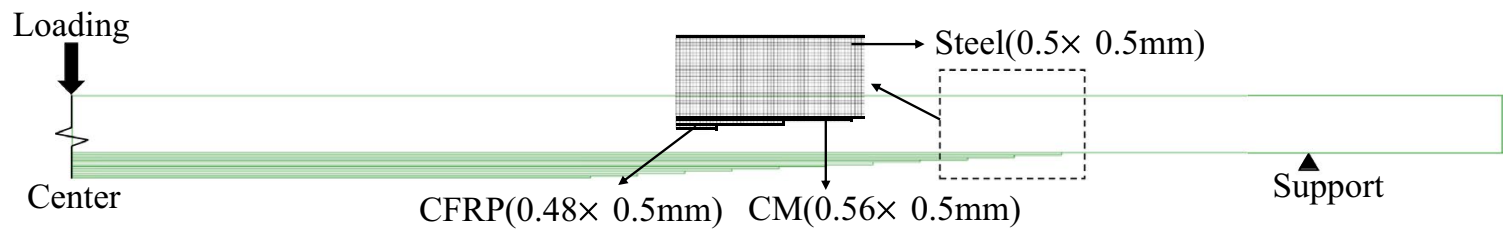

Fig. 16 The FEA model of three-point bending test

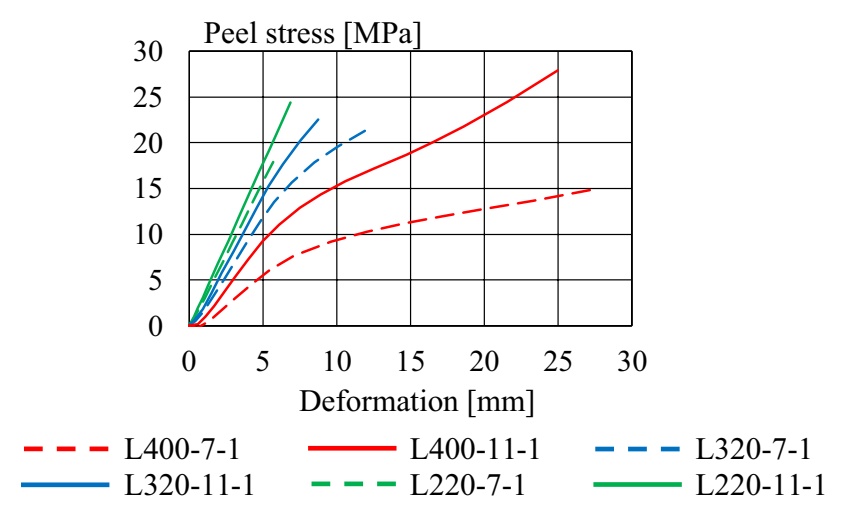

Fig. 17 The peel stress-deformation relationship obtained by FEA

Figure 13 also shows the results of FEA, and the results are almost corresponding to the experimental results. From these results, it was found that a reinforcing effect was not exerted in the case of where the bonding length is extremely short, but FEA could simulate the effects. Based on these factors, it is considered that the bending behavior was different between the $L 220$ specimens and the $L 320$ specimens debonding of CFRP occurred. Secondly, the fracture modes were analyzed. Figure 18 shows the peel stress-strain relationships by FEA. Its strain is the same position of SG3. As can be seen from Fig. 17, it can be confirmed that the peel stress at the time of debonding of the L220 specimens and L320 specimens is about $20 \mathrm{MPa}$. From this result, it is estimated that debonding failure occurs when the peel stress reaches about $20 \mathrm{MPa}$ in this experimental condition. The debonding failure occurred by not only peel stress but also other stress component [15]; especially shear stress severely affects the debonding failure, so the failure stress should be determined by the various sectional shape, loading condition as well as stiffness of steel and/or CFRP as a subject of future investigation. On the other hand, focusing on the $L 400$ specimens in which the breaking of CFRP at the center occurred, L400-7-1 reached the breaking strain of CFRP at the center before reaching the peel stress of $20 \mathrm{MPa}$ as shown in Fig. 18. From the results of L400-11-1 in Fig. 18, it is found that the peel stress of $20 \mathrm{MPa}$ is generated when the strain of CFRP reaches about $7000 \mu$. The breaking strain of CFRP in the experiment was visually confirmed when it exceeded $8000 \mu$; however, the nominal breaking strain of the carbon 


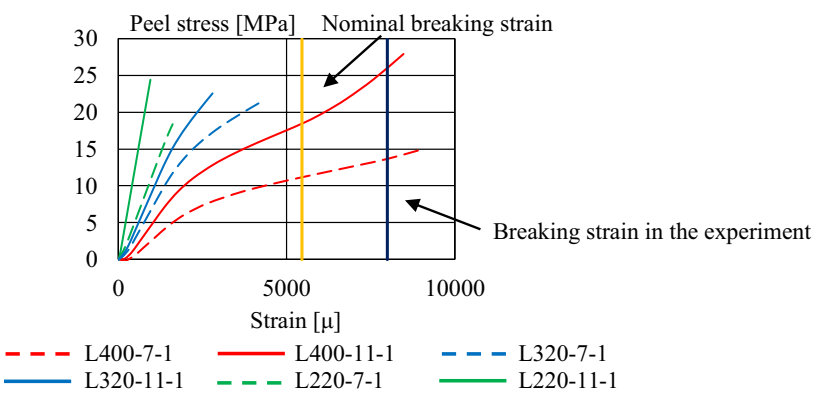

Fig. 18 The peel stress-strain relationship obtained by FEA. Also, in the figure, the nominal breaking strain of CFRP and the breaking strain at the experiment are shown

fiber sheet in this study was about $5400 \mu$; it was considered that the bending elastic modulus is lower than the fiber axial direction elastic modulus; it is supposed that the breaking of CFRP at the center occurred before the peel stress reached $20 \mathrm{MPa}$ or in the same load step. In that case, it is considered that the bending stiffness decreases because of the breaking of the carbon fiber at the center, and the peel stress was also slightly decreased. As a result, the L400-11 specimens reached peel stress of $20 \mathrm{MPa}$, which is expected to result in debonding in the case of FEA; however, the debonding did not occur through all L400-11 specimens, resulting in the breaking of CFRP.

\section{Conclusions}

In this study, the VaRTM method was applied as an adhesive bonding method for repair/reinforcement to steel structural members. Steel/CFRP hybrid specimens were prepared by VaRTM, and bond strength and mechanical behavior were analyzed and evaluated using elastic theory and finite element analysis through a double-strap tensile shear test and a three-point bending test. The findings obtained are shown below.

(1) It is demonstrated that high fiber volume content and stable CFRP molding adhesion are possible by the VaRTM method.

(2) It showed that by applying the impregnating resin beforehand to the adhering surface before setting up the reinforcing material, it leads to stability of bond strength.

(3) For the elastic behavior, the initial stiffness shows correspondence with the beam theory, indicating that the bending stiffness increases. Also, it is confirmed that FEA can simulate the effects of CFRP-strengthened steel with high accuracy even if the complex lamination condition was adopted.
(4) Analysis of bond strength and fracture mode of specimens with different bonding length and number of laminations using by finite element analysis, it was estimated the peel stress caused debonding was around $20 \mathrm{MPa}$ without the effects of shear stress. And, it was confirmed that the FEA results corresponded to experimental result. In addition, it showed that the breaking of CFRP can occur before debonding because of the increase in bonding length.

Acknowledgements This work was supported by MLIT Construction Technology Research and Development Subsidy Program.

\section{Compliance with ethical standards}

Conflict of interest This study was funded by "Construction Technology Research and Development Subsidy Program" of Japan Ministry of landscape, infrastructure and tourism. The authors declare that they have no conflict of interest.

\section{References}

1. Fujino $Y$, Kawai $Y$ (2016) Technical developments in structural engineering with emphasis on steel bridges in Japan. J JSCE 4:211-226

2. Chen K, Nakamura S, Chen B, Qingxiong W, Nishikawa T (2013) Comparison between steel arch bridges in China and Japan. J JSCE 1:214-227

3. Koh H-M, Choo JF (2009) Preparation for the next generation of bridge technology in Korea. Struct Eng Earthq Eng JSCE 26(1):1s-12s

4. Zhao X-L, Zhang L (2004) State-of-the-art review on FRP strengthened steel structures. Eng Struct 29:1808-1823

5. Meier U (2000) Composite materials in bridge repair. Appl Compos Mater 7:75-94

6. Nagai M, Hidekuma Y, Miyashita T, Okuyama Y, Kudo A, Kobayashi A (2012) Bonding characteristics and flexural stiffening effect of CFRP strand sheets bonded to steel beams. Proc Eng 40:137-142

7. Uddin N (2013) Developments in fiber-reinforced polymer (FRP) composites for civil engineering. Woodhead Publishing, Cambridge

8. Streitferdt A, Rudolph N, Taha I (2017) Co-Curing of CFRP-steel hybrid joints using the vacuum assisted resin infusion process. Appl Compos Mater 24:1137-1149

9. Jeoung SK, Hwang YJ, Lee HW, Son SK, Kim HS, Ha JU (2016) Study on properties of CFRP fabricated by VA-RTM process. AIP Conf Proc 1713(120016):1-5

10. Haghani R, Al-Emrani M, Kliger R (2009) Stress distribution in adhesive joints with tapered laminates: effect of tapering length and material properties. J Compos Mater 44(3):287-302

11. Stango RJ, Fournelle RA, Martinez JA (2011, March) Bristle blast surface treatment of welded joints fabricated from commercial ship construction steel. Proceedings of NACE corrosion 2011, Houston 
12. Bank LC (2006) composites for construction: structural design with FRP material. Wiley, Hoboken

13. Jiao H, Zhao X-L (2004) CFRP strengthened butt-welded very high strength (VHS) circular steel tubes. Thin Walled Struct 42:963-978

14. Siwowski TW, Pasko P (2016, Dec) Flexural strengthening of steel beams with passive and active CFRP plates. Proceeding of eighth international conference on steel and aluminum structures, Hong Kong
15. Deng J, Lee MMK (2007) Fatigue performance of metallic beam strengthened with a bonded CFRP plate". Compos Struct 78(2):222-231

Publisher's Note Springer Nature remains neutral with regard to jurisdictional claims in published maps and institutional affiliations. 